\title{
Genomic Evidence of In-Flight Transmission of SARS-CoV-2 Despite Predeparture Testing
}

Tara Swadi, ${ }^{1}$ Jemma L. Geoghegan, ${ }^{1}$ Tom Devine, Caroline McElnay, Jillian Sherwood, Phil Shoemack, Xiaoyun Ren, Matt Storey, Sarah Jefferies, Erasmus Smit, James Hadfield, Aoife Kenny, Lauren Jelley,

Andrew Sporle, Andrea McNeill, G. Edwin Reynolds, Kip Mouldey, Lindsay Lowe, Gerard Sonder, Alexei J. Drummond, Sue Huang, David Welch, Edward C. Holmes, Nigel French, Colin R. Simpson, Joep de Ligt

Since the first wave of coronavirus disease in March 2020 , citizens and permanent residents returning to New Zealand have been required to undergo managed isolation and quarantine (MIQ) for 14 days and mandatory testing for severe acute respiratory syndrome coronavirus 2 (SARS-CoV-2). As of October 20, 2020, of 62,698 arrivals, testing of persons in MIQ had identified 215 cases of SARS-CoV-2 infection. Among 86 passengers on a flight from Dubai, United Arab Emirates, that arrived in New Zealand on September 29, test results were positive for 7 persons in MIQ. These passengers originated from 5 different countries before a layover in Dubai; 5 had negative predeparture SARS-CoV-2 test results. To assess possible points of infection, we analyzed information about their journeys, disease progression, and virus genomic data. All 7 SARS-CoV-2 genomes were genetically identical, except for a single mutation in 1 sample. Despite predeparture testing, multiple instances of in-flight SARS-CoV-2 transmission are likely.

Author affiliations: New Zealand Ministry of Health, Wellington, New Zealand (T. Swadi, T. Devine, A. Kenny); University of Otago, Dunedin, New Zealand (J.L. Geoghegan); Institute of Environmental Science and Research, Porirua, New Zealand (J.L. Geoghegan, J. Sherwood, X. Ren, M. Storey, S. Jefferies, E. Smit, L. Jelley, A. McNeill, G. Sonder, S. Huang, J. de Ligt); New Zealand Ministry of Health, Wellington (C. McElnay); Bay of Plenty District Health Board, Tauranga, New Zealand (P. Shoemack, K. Mouldey, L. Lowe); Fred Hutchinson Cancer Research Centre, Seattle, Washington, USA (J. Hadfield); University of Auckland, Auckland, New Zealand (A. Sporle, A.J. Drummond, D. Welch); iNZight Analytics Ltd., Auckland (A. Sporle); Auckland District Health Board, Auckland (G.E. Reynolds); The University of Sydney, Sydney, New South Wales, Australia (E.C. Holmes); Massey University, Palmerston North, New Zealand (N. French); Victoria University of Wellington, Wellington (C.R. Simpson); University of Edinburgh, Edinburgh, UK (C.R. Simpson)
Tn response to the growing international risks as1 sociated with importation of coronavirus disease (COVID-19), on March 20, 2020, New Zealand closed its borders to all but New Zealand citizens, permanent residents, and persons with an exemption (1). On April 9, 2020, to better control importation risks, New Zealand implemented a system of managed isolation and quarantine (MIQ) at the border. Persons arriving in New Zealand were required to stay in a government-assigned MIQ facility for at least 14 days before entering the New Zealand community. In June 2020, a system of testing persons who were returning to New Zealand and staying in MIQ facilities was instituted; nasopharyngeal swabs were taken on approximately the third and the twelfth day of the quarantine period and from anyone in whom symptoms developed or those identified as close contacts of persons with severe acute respiratory syndrome coronavirus 2 (SARS-CoV-2) positive test results.

On September 29, 2020, flight EK448, which originated in Dubai, United Arab Emirates, with a stop in Kuala Lumpur, Malaysia, landed in Auckland, New Zealand. During the required 14-day MIQ period, 7 passengers who had traveled on the flight received positive SARS-CoV-2 test results. The 7 passengers had begun their journeys from 5 different countries before a layover in Dubai; predeparture SARS-CoV-2 test results were negative for 5 (Figure 1). These 7 passengers had been seated within 4 rows of each other during the $\approx 18$-hour flight from Dubai to Auckland. Because recent studies have reported conflicting findings of the risks associated with in-flight transmission (2-4), we undertook a comprehensive investigation to determine the potential source of infection of these travelers. 


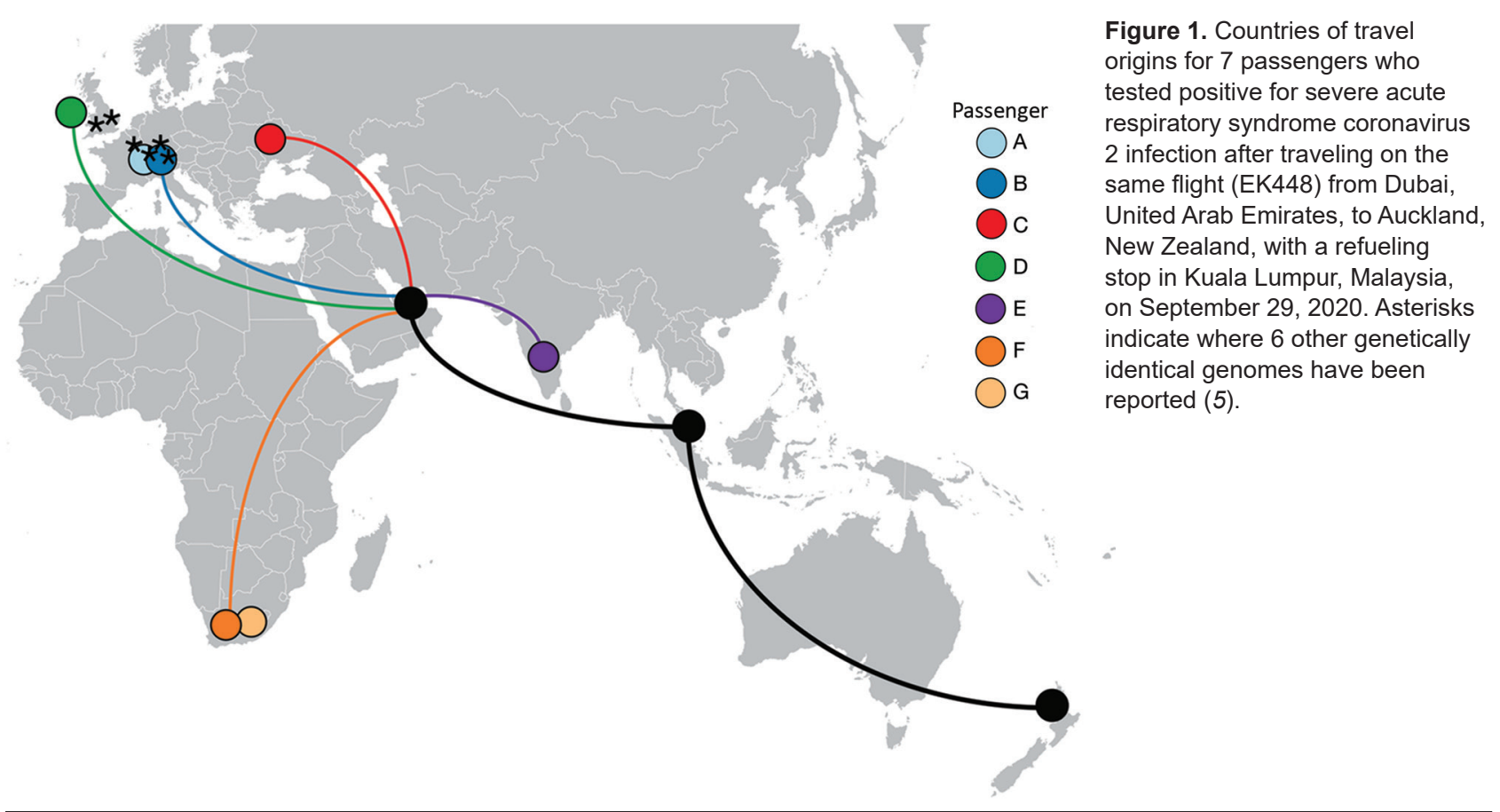

\section{Methods}

\section{Case Details and Consent}

In New Zealand, COVID-19 is a notifiable disease; all positive cases are reported to the national surveillance system, enabling further public health investigation. All persons with COVID-19 described in this article were contacted, and they provided written or verbal consent for their data to be used in this article. Case data were collected under the Ministry of Health contract for epidemic surveillance. The 7 persons with COVID-19 are denoted here as passengers A-G (Tables 1, 2).

\section{Clinical Data and Sample Collection}

Case details were sourced from the national notifiable diseases database, EpiSurv (https://surv.esr. cri.nz/episurv/index.php). While in MIQ, all 86 passengers on the flight underwent real-time reverse transcription PCR (rRT-PCR) diagnostic testing for SARS-CoV-2 on day 3 and again on day 12 if the previous test result was negative. Cabin crew members departed New Zealand soon after their arrival and were therefore not tested. Investigations used information from rRT-PCR testing by using the Cepheid GeneXpert system (https://www.cepheid.com) and BD Max (https://www.bd.com). We determined seating plans by consulting the flight manifest for the Boeing 777-300ER aircraft and confirmed them by administering a questionnaire to passengers, asking where they actually sat.

\section{Genome Sequencing}

Independent viral extracts were prepared by the Institute of Environmental Science and Research (Porirua, New Zealand) from the 7 positive respiratory tract samples in which SARS-CoV-2 was initially detected by rRT-PCR. We extracted RNA from SARSCoV-2-positive samples and subjected it to whole-genome sequencing by following the 1,200-bp amplicon protocol (6) and Oxford Nanopore Rapid barcoding R9.0 sequencing (7). Genomic data are available on GISAID (5) (Table 1).

\section{Phylogenetic Analysis of SARS-CoV-2 Genomes}

The lineage of the genomes obtained from the 7 passengers was determined by using pangolin version 2.0.8 (https:/ / pangolin.cog-uk.io) and compared with genomes from the same lineage available on GISAID (5). Genomes were aligned by using MAFFT version 7 (8) and using the FFT-NS-2 progressive alignment algorithm. We estimated a maximum-likelihood phylogenetic tree by using IQ-TREE version 1.6.8 (9) and the Hasegawa-Kishino-Yano nucleotide substitution model (10) with a gamma distributed rate variation among sites $(\mathrm{HKY}+\Gamma)$, the best-fit model as determined by ModelFinder (11), and branch support assessment by using the ultrafast bootstrap method (12).

\section{Analysis of Disease Transmission Data}

All times and dates reported here were converted to New Zealand daylight savings time (Greenwich mean time +13 hours) (Table 2). The mean incubation 
period, defined as the duration between estimated dates of infection and reported symptom onset, has been reported as 5-6 days (range 1-14 days) (13). We assumed a 5-day incubation period for passengers $A, B, D, E, F$, and $G$, and a 3-day incubation period for passenger $C$. We considered the median presymptomatic infectious period to be $<1-4$ days unless a negative PCR result indicated otherwise (14).

\section{Results}

\section{The Flight}

Flight EK448 from Dubai, UAE to Auckland, New Zealand, was an 18-hour, 2-minute flight on a Boeing 777-300ER aircraft. It departed Dubai on September 28, 2020, at 5:29 PM; arrived in Kuala Lumpur on September 29 at 12:11 AM to refuel; and departed Kuala Lumpur on September 29 at 2:03 AM. No passengers entered or exited the aircraft during the 2-hour refueling period in Kuala Lumpur. The flight arrived in Auckland on September 29 at 11:31 AM. During the flight and before departure in Dubai airport, mask use was not mandatory; passengers $A, B, D, F$, and $G$ self-reported mask and glove use while on the airplane but passengers $\mathrm{C}$ and $\mathrm{E}$ did not. In the days before the flight, these 7 passengers (other than the 2 travel groups, 1 of which comprised passengers $\mathrm{A}$ and $\mathrm{B}$ and the other passengers $F$ and $G$ ) had been in different countries and did not have any form of contact (Figure 1). Similarly, none of the passengers reported having been in close contact at the Dubai airport. Passengers $F$ and $G$ were part of a family travel group of 4 , all of whom reported having changed seats within their row during the flight.

All passengers, with the exception of passenger E, were transferred by bus to an MIQ facility in Rotorua, New Zealand. All passengers reported wearing masks during the bus journeys. Passengers A, B, and $D$ were on bus 1 ; passengers $F$ and $G$ were on bus 2 . Passenger $C$ was initially seated on bus 1 but was transferred to bus 2 before transit. Both buses departed Auckland at 12:05 PM and arrived in Rotorua at 3:00 PM. Passenger E traveled on bus 3 to an MIQ facility in Auckland. Seating on all buses was physically distanced where possible, and mask use was mandated.

\section{Testing and Disease Progression}

Five passengers reported having received negative test results before departure (Table 1). A negative test result was mandatory according to airline regulations for passenger $\mathrm{C}$, who traveled from Ukraine.

The first 3 passengers to receive positive SARSCoV-2 test results (passengers $\mathrm{A}, \mathrm{B}$, and $\mathrm{C}$ ) were

Table 1. Detailed information for 7 passengers with SARS-CoV-2 infection detected after being on flight EK448, Dubai, United Arab Emirates, to Auckland, New Zealand, September 29, 2020*

\begin{tabular}{|c|c|c|c|c|c|c|c|}
\hline \multirow[b]{2}{*}{ Variable } & \multicolumn{7}{|c|}{ Passenger } \\
\hline & A & $\mathrm{B}$ & $\mathrm{C}$ & $\mathrm{D}$ & $\mathrm{E}$ & $F$ & $\mathrm{G}$ \\
\hline Genome & Identical & Identical & Identical† & $\begin{array}{l}1 \text { additional } \\
\text { mutation }\end{array}$ & Identical & Identical & Identical \\
\hline $\begin{array}{l}\text { Genome ID (GISAID } \\
\text { accession no.) (5) }\end{array}$ & $\begin{array}{l}\text { 20CV0408 } \\
\text { (EPI_ISL_- } \\
582019)\end{array}$ & $\begin{array}{l}\text { 20CV0409 } \\
\text { (EPI_ISL_- } \\
582020)\end{array}$ & $\begin{array}{l}20 C V 0410 \\
\text { (EPI_ISL_- } \\
582021)\end{array}$ & $\begin{array}{c}\text { 20CV0401 } \\
\text { (EPI_ISL_- } \\
582018)\end{array}$ & $\begin{array}{l}\text { 20CV0398 } \\
\text { (EPI_ISL_- } \\
582017)\end{array}$ & $\begin{array}{c}\text { 20CV0414 } \\
\text { (EPI_ISL_- } \\
582022)\end{array}$ & $\begin{array}{l}\text { 20CV0415 } \\
\text { (EPI_ISL_- } \\
582023)\end{array}$ \\
\hline $\begin{array}{l}\text { Preflight testing result } \\
\text { (date) } \ddagger\end{array}$ & $\begin{array}{l}\text { Negative } \\
\text { (Sep 24) }\end{array}$ & $\begin{array}{l}\text { Negative } \\
\text { (Sep 24) }\end{array}$ & $\begin{array}{l}\text { Negative } \\
\text { (Sep 25) }\end{array}$ & $\begin{array}{l}\text { Negative } \\
\text { (Sep 24) }\end{array}$ & Not tested & $\begin{array}{l}\text { Negative } \\
\text { (Sep 25) }\end{array}$ & Not tested \\
\hline Symptom onset date & Oct 1 & Oct 2 & Asymptomatic & Oct 4 & Asymptomatic & Oct 3 & Oct 9 \\
\hline Date tested positive & Oct 2 & Oct 2 & Oct 2 & Oct 7 & Oct 6 & Oct 8 & Oct 8 \\
\hline Technology§ and $\mathrm{C}_{\mathrm{t}}$ & $\begin{array}{c}\text { GeneXpert, } \\
\text { E-gene } C_{t} \\
14.3, N 2- \\
\text { gene } C_{t} 16.4\end{array}$ & $\begin{array}{c}\text { GeneXpert, } \\
\text { E-gene } C_{t} 27, \\
\text { N2-gene } C_{t} \\
29.3\end{array}$ & $\begin{array}{c}\text { GeneXpert, } \\
\text { E-gene } C_{t} \\
\text { 33.3, N2-gene } \\
C_{t} 36.8\end{array}$ & $\begin{array}{c}\text { GeneXpert, } \\
\text { E-gene } C_{t} \\
18.5 \text { N2-gene } \\
C_{t} 20.4\end{array}$ & $\begin{array}{c}\text { GeneXpert, } \\
\text { E-gene } C_{t} \\
18.5, \text { N2 gene } \\
C_{t} 22.3\end{array}$ & $\begin{array}{c}\text { BD Max, } \\
\text { N1-gene } C_{t} \\
22.0 \text { N2-gene } \\
C_{t} 22.3\end{array}$ & $\begin{array}{c}\text { BD Max, } \\
\text { N1-gene } C_{t} \\
22.1, \text { N2-gene } \\
C_{t} 19.1\end{array}$ \\
\hline Country of origin & Switzerland & Switzerland & Ukraine & Ireland & India & South Africa & South Africa \\
\hline Layover time in Dubai & $9 \mathrm{~h} 27 \mathrm{~min}$ & $9 \mathrm{~h} 27 \mathrm{~min}$ & $11 \mathrm{~h} 30 \mathrm{~min}$ & $8 \mathrm{~h} 18 \mathrm{~min}$ & 70 h 54 min & $5 \mathrm{~h} 44 \mathrm{~min}$ & $5 \mathrm{~h} 44 \mathrm{~min}$ \\
\hline Seat no. on flight & $26 G$ & $26 \mathrm{D}$ & $24 \mathrm{C}$ & $27 \mathrm{D}$ & $28 \mathrm{G}$ & $24 \mathrm{D} /$ & $E / F / G$ \\
\hline $\begin{array}{l}\text { PPE worn on airplane } \\
\text { and bus } \ddagger\end{array}$ & $\begin{array}{l}\text { Face mask } \\
\text { and gloves }\end{array}$ & $\begin{array}{c}\text { Face mask } \\
\text { and glovesף }\end{array}$ & Not reported & $\begin{array}{l}\text { Face mask } \\
\text { and gloves }\end{array}$ & Not reported & Face mask & Face mask \\
\hline $\begin{array}{l}\text { Bus from airport to } \\
\text { MIQ\# }\end{array}$ & Bus 1 & Bus 1 & $\begin{array}{l}\text { Bus } 1 \text { briefly, } \\
\text { transported } \\
\text { on bus } 2\end{array}$ & Bus 1 & Bus 3 & Bus 2 & Bus 2 \\
\hline
\end{tabular}

*GISAID, https://www.gisaid.org. $\mathrm{C}_{t}$, cycle threshold; MIQ, managed isolation and quarantine; PPE, personal protective equipment.

†Partial genome obtained (1 amplicon failed, resulting in 1,200 ambiguous nucleotide bases) but has the 5 defining mutations of the cluster.

$\ddagger$ Self-reported.

§GeneXpert, https://www.cepheid.com; BD Max, https://www.bd.com.

TReportedly removed when sleeping and seated.

\#Social distancing and mandated mask wearing on all buses. 
Table 2. Travel times for 7 passengers with SARS-CoV-2 infection detected after being on flight EK448, Dubai, United Arab Emirates, to Auckland, New Zealand, September 29, 2020

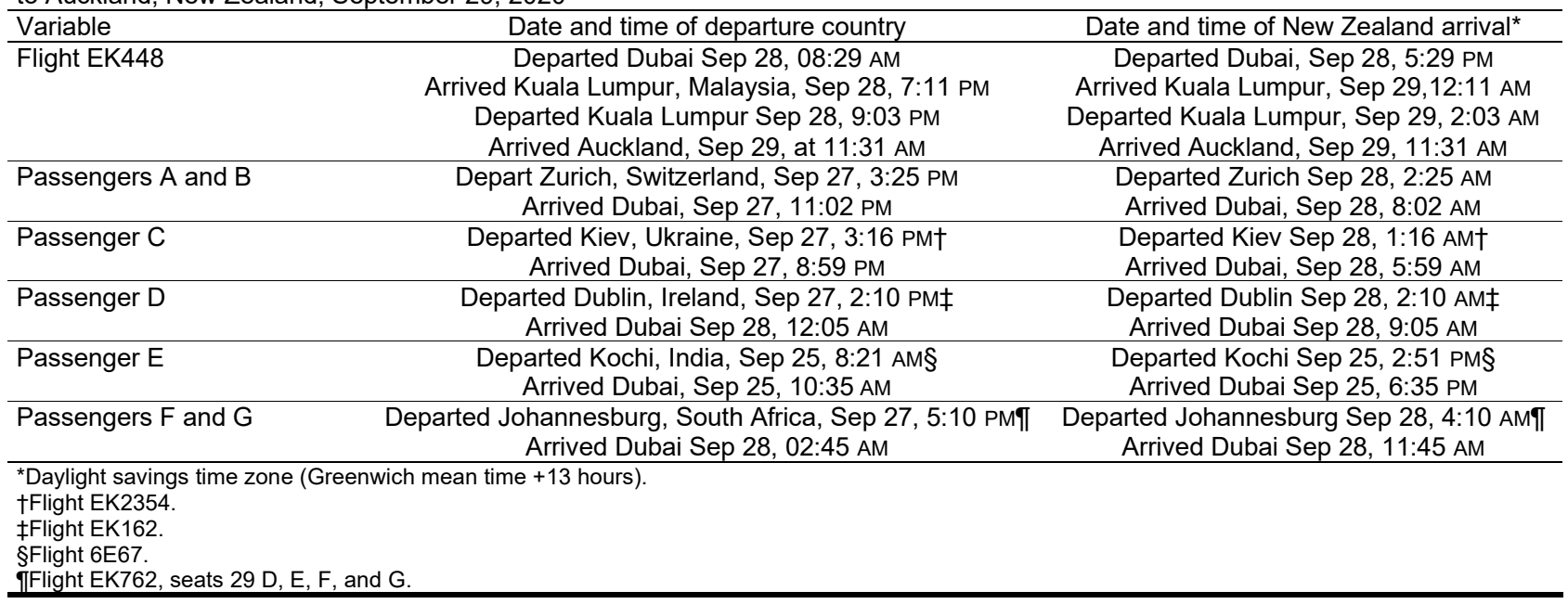

identified through routine surveillance testing on the third day of the quarantine period in New Zealand (Figure 2). Passengers A and B traveled together from Switzerland; both reported having had negative test results in their country of origin, $\leq 72$ hours before boarding the flight. They departed Zurich, Switzerland, and arrived in Dubai on September 28, 2020, at 08:02 AM. Passenger A reported symptom onset (general weakness and muscle pain) while in MIQ on October 1, and passenger B reported symptom onset (rhinorrhea, general weakness, cough, and muscle pain) on October 2. Test results for samples collected on October 2 from both persons were positive.

Test results for passenger $C$ were also positive on October 2, but the passenger did not report symptoms at any time during the infection. This person had traveled from Kiev, Ukraine, and arrived in Dubai on September 28 at 5:59 AM.

Test results for passenger $\mathrm{D}$ were negative on October 2, but the passenger reported symptoms on the fifth day after arrival in New Zealand. The symptoms progressively worsened, and another test on October 7 returned a positive result. Reported symptoms included coryza, headache, muscle pain, general weakness, irritability, confusion, and a head cold. This passenger had departed from Dublin, Ireland, and arrived in Dubai on September 28 at 9:05 AM.

Test results for passenger $\mathrm{E}$ were negative on October 2 , but the passenger was retested on October 6 as a potential close contact of those on the airplane and found to be positive for SARS-CoV-2. This passenger was not in the same MIQ facility (nor the same city) in New Zealand as the other passengers with reported

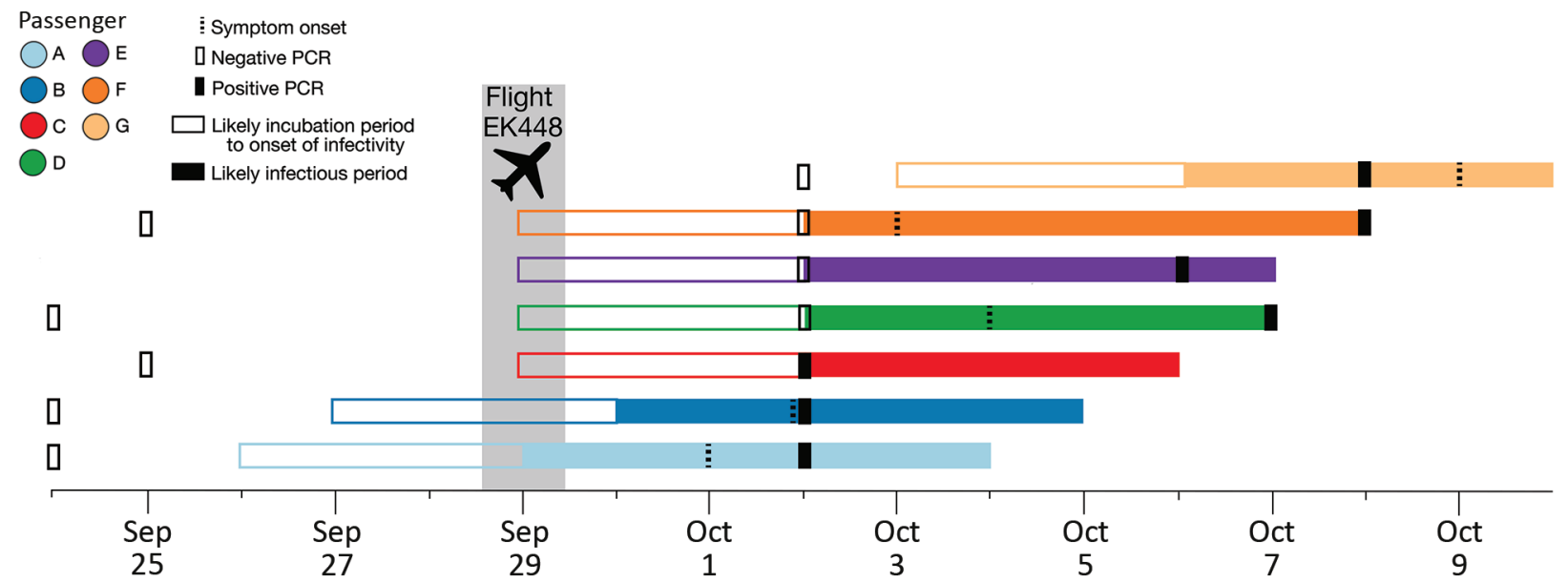

Figure 2. Timeline of likely incubation and infectious periods, indicating testing dates, for 7 passengers who tested positive for severe acute respiratory syndrome coronavirus 2 infection after traveling on the same flight (EK448) from Dubai, United Arab Emirates, to Auckland, New Zealand, with a refueling stop in Kuala Lumpur, Malaysia, on September 29, 2020. 
cases and did not report symptoms during the infection. This passenger had departed from Kochi, India, and arrived in Dubai on September 25 at 6:35 PM.

Test results for passengers $F$ and $G$ (part of a group of 4 family members traveling together) were negative on October 2 in New Zealand. Passenger F became mildly symptomatic (coryza and a cough) on October 2 and self-reported having had a negative test result before leaving South Africa. The group was retested as potential contacts of those on the flight with positive results, and on October 8, results were positive for passengers $F$ and $G$. Passenger $G$ reported coryza and a sore throat on October 9. The 4-person travel group had departed from Johannesburg, South Africa, and arrived in Dubai on September 28 at 11:45 AM. The 4 family members were seated in 4 adjacent seats in row 24 but interchanged seats within the row, such that no specific seat can be determined for each passenger (Figure 2). Test results were positive for only 2 of the 4 family members; after receiving the positive results, the persons were separated in the MIQ facility.

\section{Timeline of Transmission Events}

The first person to experience symptoms was passenger A on October 1, consistent with having been infectious while on flight EK448 2 days earlier (Figure 3). The second person to experience symptoms, on October 2, was passenger B, a travel companion of passenger $A$, which may represent shared exposure to a source $A$, such that passenger B's infection is not considered a case of in-flight transmission. Passenger $C$ was asymptomatic and received a positive test result on day 3. Symptom onset and positive test result dates for passengers $\mathrm{D}, \mathrm{E}$, and $\mathrm{F}$ were all consistent with in-flight transmission. Passenger $G$ was a travel companion of passenger $F$, and their date of

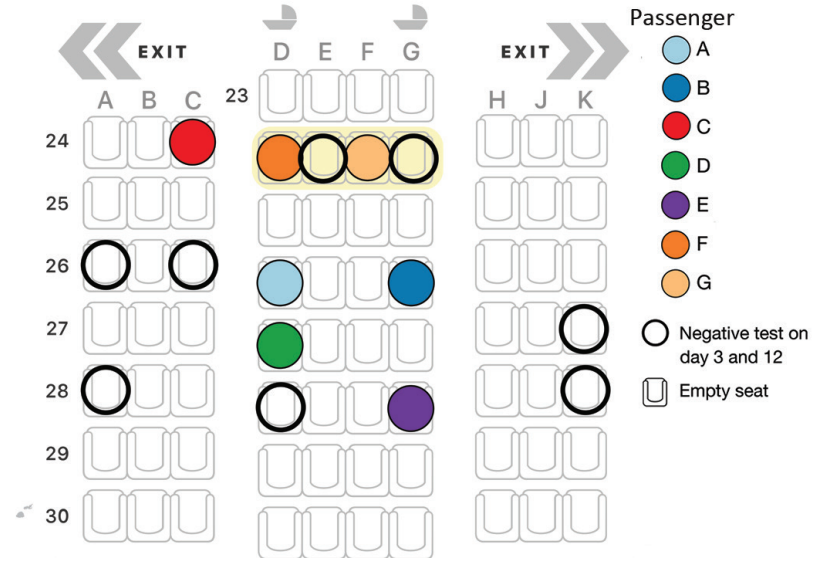

Figure 3. Seating arrangement (Boeing 777-300ER) for 7 passengers who tested positive for severe acute respiratory syndrome coronavirus 2 (SARS-CoV-2) infection on flight EK448 from Dubai, United Arab Emirates, to Auckland, New Zealand, with a refueling stop in Kuala Lumpur, Malaysia, on September 29, 2020. Passengers $F$ and $G$ interchanged seats within row 24. Open circles represent nearby passengers who were negative for SARS-CoV-2 on days 3 and 12 while in managed isolation and quarantine. All other seats shown remained empty.

symptom onset was consistent with infection during their stay in an MIQ facility, where they resided in the same room. As such, passenger G's infection was not considered a result of in-flight transmission.

\section{Viral Genomic Data}

All SARS-CoV-2 samples from the 7 passengers were subjected to whole-genome sequencing for surveillance purposes. The sequences obtained were assigned to lineage B.1 and were genetically identical, apart from 1 mutation for the sample from passenger D (Figure 4) (15). By comparing these 7 genomes to the international database (GISAID), we identified 6

Figure 4. Simplified maximumlikelihood phylogenetic tree of genomes from severe acute respiratory syndrome coronavirus 2 from 7 passengers who traveled on flight EK448 (Boeing 777300ER) from Dubai, United Arab Emirates, to Auckland, New Zealand, with a refueling stop in Kuala Lumpur, Malaysia, on September 29, 2020. Tree shows positive cases along with their closest genomic relatives sampled from the global dataset. Black circles illustrate cases obtained from the global

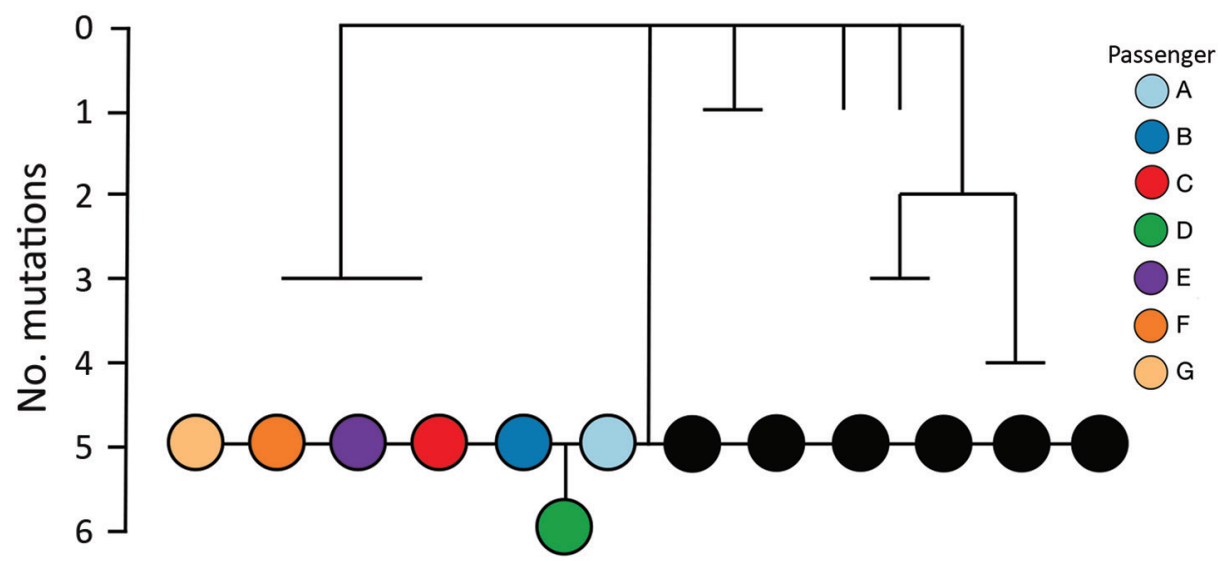
dataset that are genetically identical, sampled September 2-23, 2020. Scale bar shows the number of mutations relative to the closest reconstructed ancestor from available global data. 


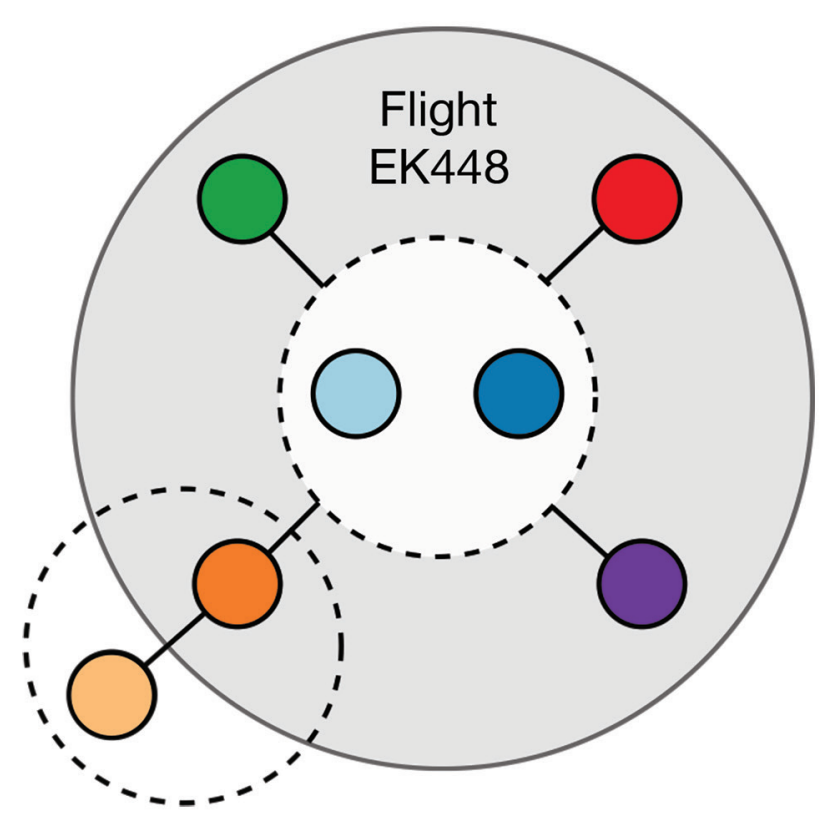

Figure 5. Network of likely severe acute respiratory syndrome coronavirus 2 (SARS-CoV-2) transmission among 7 passengers who traveled on flight EK448 (Boeing 777-300ER) from Dubai, United Arab Emirates, to Auckland, New Zealand, with a refueling stop in Kuala Lumpur, Malaysia, on September 29, 2020. The gray shaded area illustrates likely in-flight virus transmission. Dashed circles represent likely virus transmission between travel companions.

additional identical genomes: 4 from Switzerland and 2 from the United Kingdom, sampled during September 2-23. These findings were consistent with virus introduction onto the airplane from Switzerland by passenger A, B, or both (Figure 5). Nevertheless, accurately identifying the source of this outbreak may be impeded by substantial biases and gaps in global sequencing data (J. Geoghegan, unpub. data, https:/ / www.medrxiv.org/content/10.1101/2020.10.28.2022 1853v1); hence, we cannot explicitly exclude passenger $\mathrm{C}$ as the source.

\section{Discussion}

Evidence of in-flight transmission on a flight from the United Arab Emirates to New Zealand is strongly supported by the epidemiologic data, in-flight seating plan, symptom onset dates, and genomic data for this group of travelers who tested positive for SARS-CoV-2 (passengers A-G). Among the 7 passengers, 2 (A and B) were probably index casepatients infected before the flight, 4 (C, D, E, and F) were probably infected during the flight, and the remaining passenger $(G)$ was probably infected while in MIQ. All 7 passengers were seated in aisle seats within 2 rows of where the presumed index case- patient(s) were seated.

Combined, these data present a likely scenario of $\geq 4$ SARS-CoV-2 transmission events during a longhaul flight from Dubai to Auckland. These transmission events occurred despite reported in-flight use of masks and gloves. Further transmission between travel companions then occurred after the flight, in an MIQ facility.

These conclusions are supported by genome sequencing, an in-flight seating plan, and dates of disease onset. These data do not definitively exclude an alternative exposure event, such as virus transmission at the Dubai airport before boarding (e.g., during check-in or in boarding queues). However, the close proximity of the relevant passengers on board suggests that in-flight transmission is plausible.

Similar reports of SARS-CoV-2 being transmitted during flight have recently been published $(3,4,16,17)$. Those reports, along with the findings we report, demonstrate the potential for SARS$\mathrm{CoV}-2$ to spread on long-haul flights. It must also be noted that the auxiliary power unit of the flight EK448 aircraft was reported as having been inoperative for $\approx 30$ minutes during the 2-hour refueling stop in Kuala Lumpur, such that the environmental control system would not have been working during this period.

That 3 passengers had positive test results on day 3 of their 14-day quarantine period indicates some of the complexities of determining the value of predeparture testing, including the modality and timing of any such testing. Although not definitive, these findings underscore the value of considering all international passengers arriving in New Zealand as being potentially infected with SARS-CoV-2, even if predeparture testing was undertaken, social distancing and spacing were followed, and personal protective equipment was used in-flight.

This work was funded by the New Zealand Ministry of Health, Ministry of Business, Innovation and Employment (CIAF-0470), the New Zealand Health Research Council (20/1018), and ESR Strategic Innovation Fund.

\section{About the Authors}

Dr. Swadi is the chief advisor in COVID-19 at the Ministry of Health New Zealand and was a lead on the internal investigation into this series of cases. Dr. Geoghegan is an evolutionary virologist with a strong research focus on understanding how viruses emerge and spread in new populations. 


\section{References}

1. Jefferies S, French N, Gilkison C, Graham G, Hope V, Marshall J, et al. COVID-19 in New Zealand and the impact of the national response: a descriptive epidemiological study. Lancet Public Health. 2020;5:e612-23. https://doi.org/ 10.1016/S2468-2667(20)30225-5

2. International Air Transport Association. Low risk of transmission [cited 2020 Nov 1]. https:/ / www.iata.org/en/ youandiata/travelers/health/low-risk-transmission

3. Freedman DO, Wilder-Smith A. In-flight transmission of SARS-CoV-2: a review of the attack rates and available data on the efficacy of face masks. J Travel Med. 2020 Sep 25 [Epub ahead of print]. https:// doi.org/10.1093/jtm/ taaa178

4. Murphy N, Boland M, Bambury N, Fitzgerald M, Comerford L, Dever N, et al. A large national outbreak of COVID-19 linked to air travel, Ireland, summer 2020. Euro Surveill. 2020;25:200162. https:// doi.org/10.2807/1560-7917. ES.2020.25.42.2001624

5. Elbe S, Buckland-Merrett G. Data, disease and diplomacy: GISAID's innovative contribution to global health. Glob Chall. 2017;1:33-46. https://doi.org/10.1002/gch2.1018

6. Quick J. nCoV-2019 sequencing protocol V3 [cited 2020 Nov 1]. https://www.protocols.io/view/ncov-2019-sequencingprotocol-v3-locost-bh42j8y

7. Freed NE, Vlková M, Faisal MB, Silander OK. Rapid and inexpensive whole-genome sequencing of SARS-CoV-2 using $1200 \mathrm{bp}$ tiled amplicons and Oxford Nanopore Rapid Barcoding. Biol Methods Protoc. 2020;5:bpaa014. https://doi.org/10.1093/biomethods/bpaa014

8. Katoh K, Standley DM. MAFFT multiple sequence alignment software version 7: improvements in performance and usability. Mol Biol Evol. 2013;30:772-80. https://doi.org/ $10.1093 / \mathrm{molbev} / \mathrm{mst} 010$

9. Nguyen LT, Schmidt HA, von Haeseler A, Minh BQ. IQTREE: a fast and effective stochastic algorithm for estimating maximum-likelihood phylogenies. Mol Biol Evol. 2015;32:268-74. https://doi.org/10.1093/molbev/msu300

10. Hasegawa M, Kishino H, Yano T. Dating of the human-ape splitting by a molecular clock of mitochondrial DNA. J Mol Evol. 1985;22:160-74. https://doi.org/10.1007/BF02101694
11. Kalyaanamoorthy S, Minh BQ, Wong TKF, von Haeseler A, Jermiin LS. ModelFinder: fast model selection for accurate phylogenetic estimates. Nat Methods. 2017;14:587-9. https://doi.org/10.1038/nmeth.4285

12. Hoang DT, Chernomor O, von Haeseler A, Minh BQ, Vinh LS. UFBoot2: improving the ultrafast bootstrap approximation. Mol Biol Evol. 2018;35:518-22. https://doi.org/ $10.1093 / \mathrm{molbev} / \mathrm{msx} 281$

13. World Health Organization. Novel coronavirus situation report [cited 2020 Nov 1]. https:/ / www.who.int/docs/ default-source/coronaviruse/situation-reports/ 20200121-sitrep-1-2019-ncov.pdf

14. Byrne AW, McEvoy D, Collins AB, Hunt K, Casey M, Barber A, et al. Inferred duration of infectious period of SARS-CoV-2: rapid scoping review and analysis of available evidence for asymptomatic and symptomatic COVID-19 cases. BMJ Open. 2020;10:e039856. https://doi.org/10.1136/ bmjopen-2020-039856

15. Rambaut A, Holmes EC, O'Toole Á, Hill V, McCrone JT, Ruis C, et al. A dynamic nomenclature proposal for SARS-CoV-2 lineages to assist genomic epidemiology. Nat Microbiol. 2020;5:1403-7. https:/ / doi.org/10.1038/ s41564-020-0770-5

16. Choi EM, Chu DKW, Cheng PKC, Tsang DNC, Peiris M, Bausch DG, et al. In-flight transmission of SARS-CoV-2. Emerg Infect Dis. 2020;26:2713-6. https://doi.org/10.3201/ eid2611.203254

17. Speake H, Phillips A, Chong T, Sikazwe C, Levy A, Lang J, et al. Flight-associated transmission of severe acute respiratory syndrome coronavirus 2 corroborated by wholegenome sequencing. Emerg Infect Dis. 2020;26:2872-80. https://doi.org/10.3201/eid2612.203910

Address for correspondence: Joep de Ligt, Institute of Environmental Science and Research Ltd, Health, Bioinformatics \& Genomics, 34 Kenepuru Dr, Porirua, Wellington 5022, New Zealand; email: joep.deligt@esr.cri.nz; Jemma L. Geoghegan, University of Otago Division of Health Sciences, Microbiology and Immunology, 720 Cumberland St, Dunedin, Otago 9054, New Zealand; email: jemma.geoghegan@otago.ac.nz 